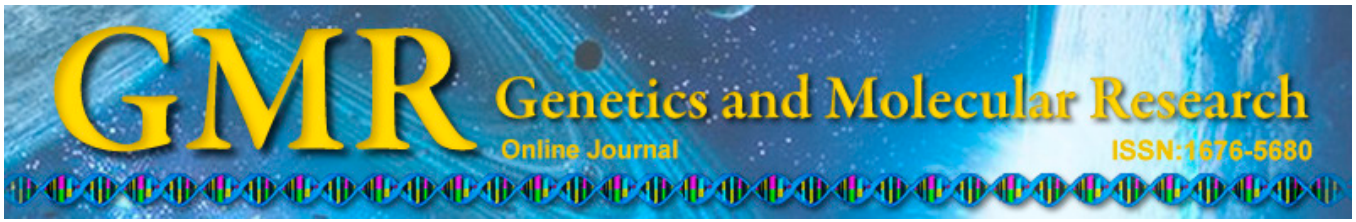

\title{
Investigating the prevention of hospital- acquired infection through standardized teaching ward rounds in clinical nursing
}

\author{
R. Zhang \\ The Nursing Department, An’tu Hospital, Shanghai, China \\ Corresponding author: R. Zhang \\ E-mail: rongzhang569@163.com
}

Genet. Mol. Res. 14 (2): 3753-3759 (2015)

Received April 22, 2014

Accepted January 23, 2015

Published April 22, 2015

DOI http://dx.doi.org/10.4238/2015.April.22.3

\begin{abstract}
This study aimed to explore the effect of standardized teaching ward rounds in clinical nursing on preventing hospital-acquired infection. The experimental group comprised 120 nursing students from our hospital selected between June 2010 and June 2012. The control group consisted of 120 nursing students selected from May 2008 to May 2010. Traditional teaching ward rounds for nursing education were carried out with the control group, while a standardized teaching ward round was carried out with the experimental group. The comprehensive application of nursing abilities and skills, the mastering of situational infection knowledge, and patient satisfaction were compared between the two groups. The applied knowledge of nursing procedures and the pass rate on comprehensive skill tests were significantly higher in the experimental group than in the control group $(\mathrm{P}<0.05)$. The rate of mastery of sterilization and hygiene procedures was also higher in the experimental group than in the control group $(\mathrm{P}<0.05)$. The patient satisfaction rate with infection control procedures in the experimental group time period was $98.09 \%$, which was significantly higher than patient satisfaction in the control group time period $(93.05 \%, \mathrm{P}<0.05)$. Standardized teaching ward rounds for nursing education expanded
\end{abstract}


the knowledge of the nursing staff in controlling hospital-acquired infection and enhanced the ability of comprehensive application and awareness of infection control procedures.

Key words: Teaching ward rounds; Nursing students; Hospital infection

\section{INTRODUCTION}

Following the development of medical science and the changes in medical models, management of hospital-acquired infections has become a systemic program, requiring the involvement of all doctors, nurses, and laboratory, service, and administrative staff (Griffiths et al., 2009; Stone et al., 2009). Control of hospital-acquired infection has also become an important reflection on the level of medical technology and the service quality of hospitals (Gao, 2008). Nursing stations are distributed in every ward and nursing service affects all procedures in a hospital (Catangui and Slark, 2012). Therefore, effective nursing management is a primary factor for controlling hospital-acquired infection, and the reinforcement of both the professional quality and comprehensive ability of nursing staff are key factors in prevention (Yokoe et al., 2008). The teaching ward round is an indispensable part of clinical nursing education (O'Hare, 2008); it can enhance the comprehensive quality of nursing students and staff, and ensure the quality of nursing services (Gao, 2008). Therefore, we standardized the teaching ward round in clinical nursing from June 2010 until June 2012, and obtained satisfactory effects on hospital-acquired infection.

\section{SUBJECTS AND METHODS}

\section{Subjects}

The experimental group included 120 female nursing students practicing in our hospital from June 2010 to June 2012, with an average age of $22.48 \pm 1.96$ years. The control group included 120 female nursing students practicing in our hospital from May 2008 to May 2010 , with an average age of $22.36 \pm 2.02$ years. All of these nursing students had completed theoretical courses in school. There was no significant difference in age, education level, or basic theory courses $(\mathrm{P}>0.05)$.

\section{Methods}

\section{Control group}

The traditional model of teaching ward rounds was applied. Nurse-led ward rounds were arranged every 2 weeks through the traditional method of teaching ward rounds. Ward rounds applied related theoretical knowledge of diseases and reinforced related knowledge of physiology, pathology, and clinical presentation of specific diseases. Possible induction causes and risk factors of hospital-acquired infection were not highlighted. There were no specific duties assigned for ward rounds, and there was no specific requirement for organizers, chairs, or participants of ward rounds. 


\section{Experimental group}

The standardized teaching ward round was performed on the experimental group. The ward round was performed every 2 weeks using multiple formats, including teaching and discussion, field experience, and case discussion. The selection qualification for teachers who chaired the teaching ward round nurses was determined: the teacher must have a degree higher than technical college, strong theoretical basis and clinical experience, and organizational and teaching abilities. The teacher was responsible for including any common diseases in the ward during student rounds, writing a teaching outline, and searching for information on nursing skill development for related diseases. The teaching ward round format was question-focused, nursing technique-focused, case-focused, and general nursing-focused. Students were required to assess their gains and provide suggestions for each ward round experience, and the teacher evaluated and discussed each round with administrators.

Rounds were designed to strengthen the standardized management of ward rounds, presenters, and participants. First, all nursing students were required to attend the discussion on focused cases in the department, complete a nursing planning report, and point out potential nurse-patient conflict. The nursing plan was then systemically observed and assessed through teaching. Second, nursing students were questioned about regulations, monitoring, detection, and methods of infection control, and were asked about their attitudes toward controlling hospital-acquired infections. Third, nursing students received on-site training about disinfection, isolation, and aseptic techniques to standardize working procedures and strategy. Intermittent guiding toward the standardization of operation and quality criteria was performed to increase the aseptic perception and self-discipline of nursing students. Fourth, during the monthly centralized nursing rounds, professional staff was responsible for monitoring the bacteria-free and treatment rooms, the surface of materials, and air quality. Any items with substandard sterilization were investigated for the cause and the responsible nursing student was criticized to ensure future standard sterilization. Finally, the teacher conducting the ward rounds introduced pre-set nursing scenarios through induction to encourage questions and positive thinking. The responsibilities associated with ward rounds included clarification of the duties of staff at different levels during ward rounds; for example, the head nurse should be familiar with the entire nursing procedure of patients in ward rounds, provide guidance for the presenter before rounds, and assess and provide feedback after completion of rounds.

\section{Evaluation of the effects}

Ability to apply nursing procedures, increased knowledge of hospital-acquired infection, the pass rate of comprehensive skill tests, and patient satisfaction were compared between the two groups. The hospital-based acquisition of infection and overall patient satisfaction were measured using a self-administered questionnaire.

\section{Statistical analysis}

Statistical analysis was completed using the SPSS 13.0 software. Categorical data are reported as percentages, and the chi-square test was used for inter-group comparison. The level of significance was set at $\alpha=0.05$. 


\section{RESULTS}

\section{Comparison of nursing procedure ability}

Due to the execution of nursing education in the recent standardized methods of managing and controlling hospital-acquired infection, as well as the comprehensive application of nursing procedures, there were no outbreaks of hospital-acquired infection during this study. The nursing students in the experimental group showed significant advantages in the accuracy of nursing diagnosis, execution rate of nursing strategy, timely rate of effective evaluation, and nursing plan pass rate compared to the control group $(\mathrm{P}<0.05)$. This suggests that the standardized method for ward rounds improved the quality of the nursing students (Table 1).

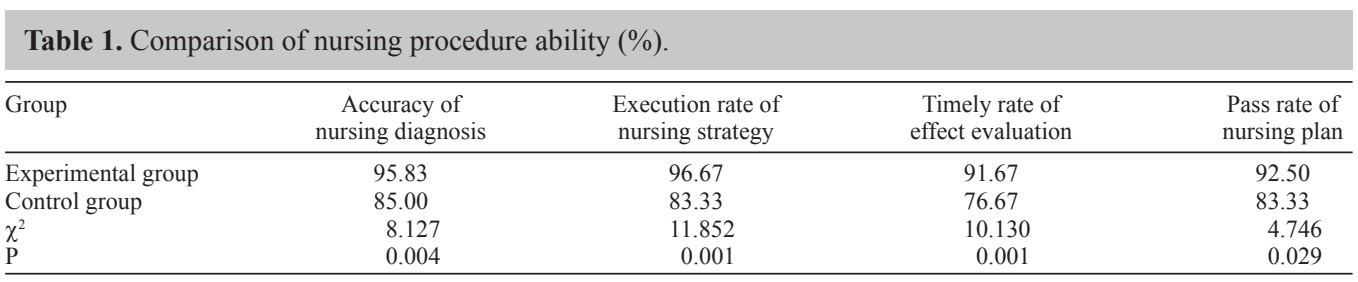

\section{Comparison of the pass rate of comprehensive skills}

After the systemic ward round, the nursing students in the experimental group showed higher scores in nursing procedures, aseptic technique, disinfection and cleaning, disinfectant use, personal protection, hand hygiene compliance, and disposal of medical waste, compared to the control group $(\mathrm{P}<0.05)$. This suggests that the standardized ward rounds curriculum enhanced students' comprehensive nursing skills, which could effectively prevent hospitalacquired infection (Table 2).

\begin{tabular}{|c|c|c|c|c|c|c|}
\hline \multirow[t]{2}{*}{ Indices } & \multicolumn{2}{|c|}{ Experimental group } & \multicolumn{2}{|c|}{ Control group } & \multirow[t]{2}{*}{$\chi^{2}$} & \multirow[t]{2}{*}{$\mathrm{P}$} \\
\hline & Pass number & Pass rate $(\%)$ & Pass number & Pass rate $(\%)$ & & \\
\hline Nursing operation procedure & 118 & 98.33 & 109 & 90.83 & 6.588 & 0.010 \\
\hline Aseptic operation & 117 & 97.50 & 110 & 91.67 & 3.985 & 0.046 \\
\hline Disinfection and cleaning & 119 & 99.17 & 110 & 91.67 & 7.717 & 0.005 \\
\hline Usage of disinfectant & 119 & 99.15 & 111 & 92.50 & 6.678 & 0.010 \\
\hline Hand hygiene compliance & 118 & 98.33 & 109 & 90.83 & 6.588 & 0.010 \\
\hline Personal protection & 118 & 98.33 & 110 & 91.67 & 5.614 & 0.018 \\
\hline Disposal of medical wastes & 117 & 97.50 & 110 & 91.67 & 3.985 & 0.046 \\
\hline
\end{tabular}

\section{Comparison of recognition of hospital-acquired infection control}

A survey of both groups' knowledge of hospital-acquired infection control indicated that the practical training and continuous reinforcement of hospital-acquired infection control procedures during standardized ward rounds had a significant effect on nursing students' ability to recognize the potential for hospital-acquired infections $(\mathrm{P}<0.05)$. However, after train- 
ing, some individual students still lacked adequate knowledge of actual techniques, such as the sequence of the disinfection and cleaning of used equipment, or the use and management of antibiotics (Table 3).

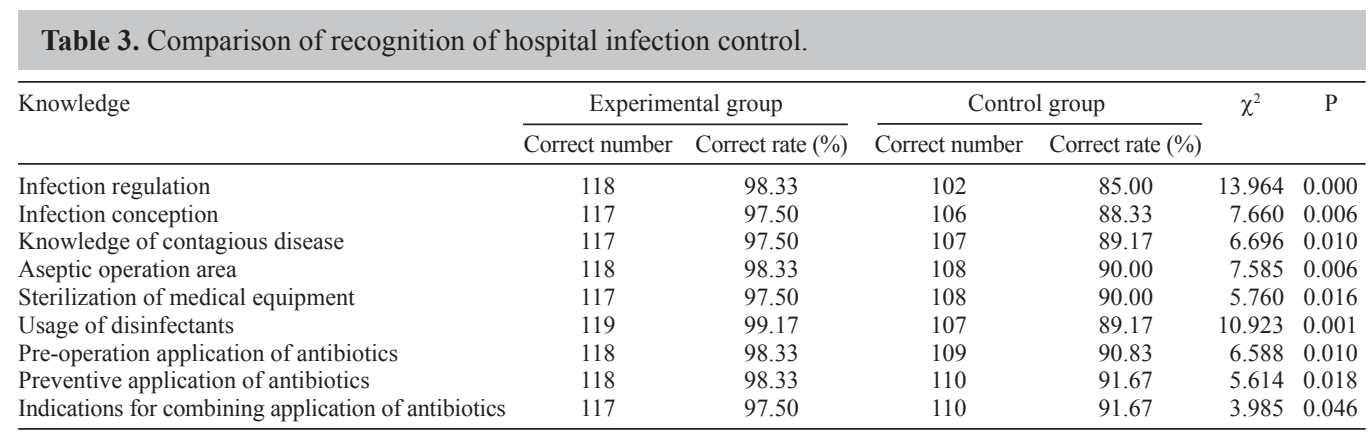

\section{Comparison of patient satisfaction to hospital-acquired infection control}

A random survey was completed assessing the satisfaction of patients with the hospital's infection control approach. The patient satisfaction rate in the control time period (2008$2010)$ and the experimental time period (2010-2012) reached 93.05 and $98.09 \%$, respectively. There was significant difference between the two groups $(\mathrm{P}<0.05$; Table 4$)$.

Table 4. Comparison of satisfaction of patients to hospital infection control.

\begin{tabular}{lccc}
\hline Group & Patient number & Satisfactory number & Satisfactory rate (\%) \\
\hline Experimental group & 1416 & 1389 & 98.09 \\
Control group & 1208 & 1124 & 93.05 \\
$\chi^{2}$ & 40.985 & & \\
$\mathrm{P}$ & 0.000 & & \\
\hline
\end{tabular}

\section{DISCUSSION}

\section{Effects of standardized teaching ward rounds on hospital-acquired infection}

Standardizing clinical education during the teaching ward round is an important step for clinical nursing education (Catangui and Slark, 2012). Our department performed a creative practice through standardized procedures of ward rounds, with multiple flexible and modern teaching methods (Zhao et al., 2009), including changes in service concept and models and the enhancement of active service consciousness. These strategies were helpful in the timely identification, prevention, and control of high-risk factors of hospital-acquired infection, and greatly enhanced the pass rates of disinfection, sterilization, and hygiene indices in our department. The hands of medical staff are an important and active transmission medium of hospital-acquired infection; incomplete hand washing among medical staff contributes to $30 \%$ of hospital-acquired infections (Sang et al., 2011). Enhancing the hand hygiene compliance of medical staff, and frequently reinforcing the knowledge of hand hygiene can promote the 
self-regulated behavior of hand washing among medical staff. These results also suggest that reinforcing the responsibility of medical staff in monitoring and management, and in aseptic procedures, could greatly reduce the rates of hospital-acquired infection.

\section{Nursing students increase their knowledge of hospital-acquired infection}

In nursing education, theoretical study is the foundation for enhancing nursing ability (Liang et al., 2008); the combination of theoretical teaching and practice enhances nurses' knowledge of hospital-acquired infection. For new nursing students, periodic knowledgebased assessment of disinfection and sterilization procedures, as well as antibiotic use should be performed. Information about decreasing hospital-acquired infection should be repeated after each nursing technique, to improve the consciousness of nursing staff regarding their role in preventing hospital-acquired infection. Specific cases should be discussed to stress the importance of controlling hospital-acquired infections in the survival and development of the hospital. During daily ward rounds, on-site practice can be performed to reinforce nursing techniques, standardize procedures, and effectively enhance the overall quality of nursing staff (Lu and Xing, 2009).

\section{Increased patient satisfaction regarding hospital-acquired infection control}

Disinfection, sterilization, aseptic technique, and timely prevention are the basis for maintaining normal medical activities in hospitals. The quality of service provided by nursing staff is closely related to patient quality-of-life (Warburton, 2009). Patients experience the medical quality of the hospital for the duration of their procedure, and patient satisfaction greatly influences the effectiveness and development of the hospital (Warburton, 2009; Vandijck et al., 2013). Therefore, the clarification of nursing staff responsibilities and roles, the regulation of hospital-acquired infection control measures, and the standardization of clinical procedures can increase nursing quality and decrease the risk of hospital-acquired infection. Our department reduced the risk factors of hospital-acquired infection and increased patient satisfaction to $98.09 \%$ by standardizing ward rounds in clinical nursing.

In summary, nursing plays a particularly important role in the management of hospitalacquired infection. The standardization of nursing ward rounds, specifically around the interaction between teachers and nurses, is an effective method to increase the quality of the nursing staff and decrease hospital-acquired infection. In future nursing ward rounds, the teacher should continuously acquire new theories and techniques to disseminate the knowledge of infection control to medical staff throughout the hospital and to reinforce the review of prevention and control policies and management procedures related to hospital-acquired infection (Zhuang et al., 2008) in order to increase the participation of medical staff in infection control.

\section{Conflicts of interest}

The author declares no conflict of interest.

\section{REFERENCES}

Catangui EJ and Slark J (2012). Nurse-led ward rounds: a valuable contribution to acute stroke care. Br. J. Nurs. 21: 801-805. 
Gao FL (2008). How are the nursing staffs involved in control of hospital infection. Chin. Nurs. Manag. 8: 72-74.

Griffiths P, Renz A, Hughes J and Rafferty AM (2009). Impact of organisation and management factors on infection control in hospitals: a scoping review. J. Hosp. Infect. 73: 1-14.

Liang LJ, Chen YY, Liang WJ and Ma QH (2008). The methods and effect of training on nursing teaching ward round for clinical tutors. Chin J. Nurs. Adm. 8: 24-28.

Lu WL and Xing GX (2009). The methods and effect of strengthening the management of hospital infection control. Chin. J. Nurs. Adm. 9: 33-34.

O'Hare JA (2008). Anatomy of the ward round. Eur. J. Intern. Med. 19: 309-313.

Sang XJ, Li SX, Li GR and Meng Q (2011). Role of nursing management in prevention and control of nosocomial infection. Chin. J. Nosocomiol. 21: 3669-3670.

Stone PW, Dick A, Pogorzelska M, Horan TC, et al. (2009). Staffing and structure of infection prevention and control programs. Am. J. Infect. Control 37: 351-357.

Vandijck D, Cleemput I, Hellings J and Vogelaers D (2013). Infection prevention and control strategies in the era of limited resources and quality improvement: a perspective paper. Aust. Crit. Care 26: 154-157.

Warburton RN (2009). Improving patient safety: an economic perspective on the role of nurses. J. Nurs. Manag. 17: 223-229.

Yokoe DS, Mermel LA, Anderson DJ, Arias KM, et al. (2008). A compendium of strategies to prevent healthcareassociated infections in acute care hospitals. Infect. Control Hosp. Epidemiol. 29: S12-S21.

Zhao Y, Xi YR and Men AM (2009). The current situation of ward rounds of clinical nursing in China. Chin. J. Nurs. Adm. 9: 21-22.

Zhuang YJ, Li KP, Yang J and Wen CR (2008). Legal standardization of nursing operation to prevent and control of hospital infection. Chin. J. Nurs. 43: 380-383. 